\title{
A NOVA EMPRESARIALIDADE E O DESENVOLVIMENTO SOCIAL NO AMBIENTE INFORMACIONAL
}

\author{
Ronny Max Machado* \\ Adalberto Simão Filho**
}

SUMÁRIO: Introdução; 1.1 A atividade empresarial sob a ótica do direito constitucional no cenário de sociedade da informação; 2 A livre concorrência, livre iniciativa e a proteção da ordem econômica; 3 Função social da empresa e sua relação com a atividade empresarial; 4 A nova empresarialidade na sociedade da informação: entre a ideologia e a utopia; 5 Considerações finais; Referências.

RESUMO: Os ramos do direito estão recebendo a influência de muitas outras áreas do conhecimento humano como, por exemplo, a filosofia, a psicologia e a sociologia. Essas relações entre as ciências humanas possibilitam o aperfeiçoamento dos institutos jurídicos e, consequentemente, o atendimento de alguns interesses comuns. Os interesses aos quais fazemos menção são os atrelados à coletividade que anseia por melhorias no plano da concretização de direitos legal e constitucionalmente assegurados. Diante deste cenário o direito empresarial passa por transformação em razão dos preceitos constitucionais - em especial, a função social da empresa e a ordem econômica e de institutos da filosofia e sociologia. Estas influências ensejaram o surgimento da denominada nova empresarialidade que, inserida no contexto de sociedade da informação, permitirá uma série de reflexões sobre seus efeitos e dilemas.

PALAVRAS-CHAVE: Sociedade da informação; Nova empresarialidade; Ideologia; Utopia.

\section{NEW ENTREPRENEURSHIP AND SOCIAL DEVELOPMENT WITHIN THE INFORMATIONAL ENVIRONMENT}

ABSTRACT: All branches of the law are affected by other areas of knowledge, such as Philosophy, Psychology and Sociology. Relationships between human sciences improve juridical institutions and, consequently, common interests linked to collectivity that desires improvement within the materialization of warranted legal and constitutional rights. Entrepreneur rights are transformed by constitutional precepts, especially, the social function of the company, and economic order and that

\footnotetext{
Mestre em Direito da Sociedade da Informação do Centro Universitário das Faculdades Metropolitanas Unidas, São Paulo, Brasil. E-mail: ronnymaxm@yahoo.com.br

* Advogado. Pós Doutor pela Universidade de Coimbra. Docente nos Programas de Pós-graduação COGEAE/ PUC-SP. Brasil.
} 
of Philosophy and Sociology. These influences triggered the emergence of a new entrepreneurship which, inserted within the context of information society, permits discussions on its effects and dilemmas.

KEY WORDS: Information Society; New Entrepreneurship; Ideology; Utopia.

\section{LA NUEVA EMPRESARIALIDAD Y EL DESARROLLO SOCIAL EN EL AMBIENTE INFORMACIONAL}

RESUMEN: Las ramas del derecho están recibiendo la influencia de muchas otras áreas del conocimiento humano como, por ejemplo, la filosofía, la psicología y la sociología. Esas relaciones entre las ciencias humanas posibilitan el perfeccionamiento de los institutos jurídicos y, consecuentemente, la atención de algunos intereses comunes. Los intereses a los cuales hacemos mención son los enganchados a la colectividad que desea por mejoras en el plan de la concretización de derechos legal y constitucionalmente asegurados. Delante de este escenario el derecho empresarial pasa por transformaciones en razón de los preceptos constitucionales - en especial, la función social de la empresa y la orden económica y de institutos de la filosofía y sociología. Estas influencias condicionaron el surgimiento de la denominada nueva "empresarialidad" que, inserida en el contexto de sociedad de la información, permitirá una serie de reflexiones sobre sus efectos y dilemas.

PALABRAS CLAVE: Sociedad de la información; Nueva "empresarialidad"; Ideología; Utopía.

\section{INTRODUÇÃO}

A nova empresarialidade decorre da atividade empresarial em movimento constante e sucessivo, exercitada no âmbito de padrões éticos e de valores objetivos que se permeiam no relacionamento com os fornecedores, mercado consumidor, agentes econômicos, valores mobiliários, trabalhadores, meio ambiente, sócios e acionistas, gerando sinergia completa e complexa que culmina em vivificar a empresa e agregar valor real.

Por outro lado, o acesso à internet como um dos elementos essenciais ao exercício da cidadania ${ }^{03}$, juntamente com a liberdade de expressão e privacidade

\footnotetext{
$\overline{{ }^{03} \text { Conforme dispõe o }}$ artigo art. $7^{\circ}$ da Lei 12.965/14
} 
com clara contribuição para o desenvolvimento da personalidade, formam a disciplina do uso da internet no Brasil, reconhecendo-se não só a escala mundial da rede, no tocante a abrangência de suas complexas relações e ramificações, como também prestigiando os princípios da livre iniciativa e da livre concorrência, verificados no âmbito do respeito aos direitos humanos à pluralidade e diversidade.

A nova empresarialidade, vista aqui como uma forma de exercício da atividade empresarial por meio do prestígio de valores éticos e morais, além da responsabilidade social, sofreu o impacto das normas da Constituição Federal de 1988, permitindo a abordagem da atividade empresarial sob a ótica dos direitos fundamentais, cooperativismo e solidarismo em um cenário da sociedade da informação.

Os fundamentos da ordem econômica, dentre eles, a livre iniciativa, livre concorrência e proteção da ordem econômica, refletem-se na atividade empresarial, trazendo valores cada vez mais relevantes para o exercício desta. Assim, forma-se o ambiente propício para o realce da nova empresarialidade, a partir do compromisso empresarial com a responsabilidade social e com os valores ético e moral, como mencionado, como forma de contribuição real ao desenvolvimento social e econômico sustentável do país,

O tratamento da nova empresarialidade, à luz da Constituição Federal de 1988, suscita um dilema central: seria uma perspectiva ideológica que se busca dentro da atividade empresarial; ou seria um discurso utópico, vez que a atividade empresarial visa eminentemente o lucro?

O lucro é, prima facie, o interesse primordial das empresas ${ }^{04}$ e, sua relação com as tecnologias e a ciência da informação propiciam uma propulsão no ganho de capital. A perspectiva utópica da nova empresarialidade trata da inviabilidade e impossibilidade de alcançar uma conduta empresarial ética pautada em objetivos, entre os quais, não transgredir normas e garantias constitucionais e violar direitos humanos.

A perspectiva ideológica trata a nova empresarialidade como uma relação entre fundamentos da ordem econômica e a criação de padrões éticos de conduta, por meio do uso de tecnologias e, por sua vez, possibilitará uma mudança nas condutas da atividade empresarial.

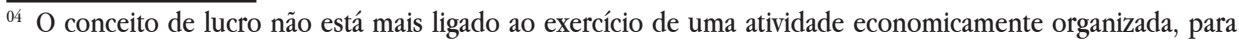
partilha entre sócios, mas a um fim de caráter social, denominado empresarialidade". ALVES, Luiz Rodrigo Pires de Oliveira. Inter-relacionamento: empresa privada e terceiro setor. In: TARREGA, Maria Cristina Vidotte Blanco; VIDOTTE, Adriana; TAVARES NETO, José Quirino (Org.). Estado, empresa e desenvolvimento econômico. Florianópolis: Fundação Boiteux, 2008, p. 307.
} 
A escolha temática tem por justificativa seu aspecto reflexivo em face do instituto da nova empresarialidade e o seu papel perante a atividade empresarial. Ademais, observou-se durante a análise encetada no trabalho o método indutivo, partindo-se da análise dos institutos jurídicos da livre iniciativa, livre concorrência e função social da empresa, bem como das doutrinas jurídicas sobre estes, para o reconhecimento do necessário e específico aprofundamento acerca da nova empresarialidade e seu papel perante a atividade empresarial em um contexto de sociedade da informação.

\subsection{A ATIVIDADE EMPRESARIAL SOB A ÓTICA DO DIREITO CONSTITUCIONAL EM UM CENÁRIO DE SOCIEDADE DA INFORMAÇÃO}

A expressão sociedade da informação começa a ser utilizada a partir do surgimento da rede Arpanet ${ }^{05}$, em 1969, nos Estados Unidos da América que ensejou os primeiros passos para o desenvolvimento tecnológico de equipamentos, principalmente em virtude da atividade militar (capacitação de agentes militares). Ademais, os centros universitários norte-americanos faziam uso de ferramentas de comunicação por meios eletrônicos que, posteriormente, conheceríamos por internet. ${ }^{06}$

No ano de 1973, o sociólogo Daniel Bell traz à tona a expressão de sociedade da informação que consiste na possibilidade de interagir e desenvolver as relações humanas. A popularização dessa ideia começa na década de 80 , viabilizando a comunicação em larga escala e cria um novo poder de natureza social.

Durante este período, a concretização da sociedade da informação ocorreu com base nas atividades desenvolvidas pelo Centro Europeu de Investigação Nuclear, sendo esta a interação feita por meio da internet. No Brasil, o Ministério da Ciência e Tecnologia, do governo federal, elaborou no ano de 1997 um documento denominado Livro Verde da Sociedade da Informação que trata da implementação e facilitação da comunicação por meio digital, dentre outras providências. Entre as características fundamentais do Livro Verde estão as normas de orientação para uso das ferramentas de comunicação por parte de seus usuários. ${ }^{07}$

\footnotetext{
${ }^{05}$ HAUBEN, Michael. Behind the net: the untold history of the ARPANET and computer science. 1995. Disponível em: < http://www.columbia.edu/ rh120/ch106.x07> . Acesso em: 01.05.2018.

${ }^{06}$ PAESANI, Liliana Minardi (Coord.). Direito e Internet: liberdade de informação, privacidade e responsabilidade civil. 6. ed. São Paulo: Atlas, 2013, p. 10.

${ }^{07}$ TAKAHASHI, Takeo (Org.). Sociedade da informação no Brasil: livro verde. Brasília: Ministério da Ciência e Tecnologia, 2000, p. 30.
} 
A globalização contribuiu para o surgimento da sociedade da informação como um modelo social, entretanto, a sobrecarga de informação que recebemos na atualidade permite um olhar dicotômico, ou seja, a percepção de que existem informações úteis e inúteis. A informação útil apenas se torna conhecimento quando ingressa no intelecto humano e, assim, ganha valor, podendo ser objeto de mercado.

Por intermédio das informações obtidas ao longo dos tempos, uma infinita geração de meios de produção foi desenvolvida, sendo que um dos atores que tem feito uso da mão de obra intelectual é o executivo de empresa. Por óbvio, existem inúmeros estabelecimentos empresariais que atuam nos mais variados segmentos, mas enfatizamos que o investimento em informação, conhecimento e tecnologia, por parte destes, é constante.

Importante frisar a relevância da informação não apenas para este segmento, mas para outros ramos do conhecimento, isto porque, muito embora a atividade empresarial valorize os dados informacionais, a esfera jurídica também reforça esta importância, vez que vários direitos estão atrelados à informação.

Roberto Senise Lisboa enfatiza acerca da compreensão minimalista que algumas pessoas possuem acerca da sociedade da informação. A compreensão deste conceito alcança não apenas uma ferramenta e um ramo do direito, mas um conjunto de mecanismos e ações que permitem a transmissão de informações em tempo real.

Não se limita a sociedade da informação, pois, ao computador ou a um direito informático, já que estende-se a qualquer meio de comunicação, presencial ou não. Assim, por exemplo: a televisão a cabo, por antena ou via satélite; o telebanking, o teleshopping e o teleworking; o rádio e o telefone. ${ }^{08}$

A denominada revolução informacional produziu uma série de efeitos, entre os quais, o fenômeno de transnacionalização e o advento dos blocos econômicos, o surgimento do e-commerce, a ideia de economicidade, a elaboração de um banco de dados, bem como a circulação de dados por meios eletrônicos e disposição de normas de caráter comunitário, conforme explica Roberto Senise Lisboa.

Os principais efeitos obtidos a partir da revolução informacional foram: 1.) A transnacionalização e o surgimento de blocos econômicos. Há um movimento sócio-econômico de integração mundial e contrário ao estabelecimento de um Estado superior, o que leva aos

\footnotetext{
${ }^{08}$ LISBOA, Roberto Senise. Proteção do consumidor na sociedade da informação. Revista do Direito Privado da UEL, v. 2, n. 1, p. 7, jan./abr. 2009. Disponível em: <www.uel.br/revistas/direitoprivado > Acesso em: 01 maio 2018.
} 
inevitáveis conflitos de interesses entre Estados e macro-empresas e seus lugares de atuação. 2.) O e-commerce, proporcionando-se a aquisição de produtos e serviços através da rede, o que ocasiona inúmeras questões sobre: - o problema da atribuição da autoria de documentos eletrônicos e da assinatura digital; - o problema da validade do documento eletrônico original e copiado; - a proteção dos direitos intelectuais, a título de propriedade industrial ou de direito autoral; - a proteção dos direitos de propriedade na web; - a oferta e a publicidade eletrônica; - os contratos eletrônicos; - a proteção do consumidor. 3.) A economicidade da informação, que possui um valor econômico reconhecido, integrando-se como ativo intelectual da pessoa e, portanto, vindo a fazer parte do patrimônio pessoal. 4.) A formação de banco de dados, extremamente útil para a análise e situações relativas a negociações preliminares, estratégias de negociação, contratos preparatórios e repercussão de eventual responsabilidade pré-contratual. 5.) A transferência eletrônica de dados, proporcionando-se o acesso à informação e o estabelecimento de novas limitações. 6.) O estabelecimento de normas comunitárias, com vistas a uma uniformização do tratamento legislativo sobre a matéria. ${ }^{09}$

Prossegue o autor aduzindo que a "Sociedade da Informação é bem mais ampla. Trata-se de um ambiente de atuação da pessoa, inclusive na órbita negocial, que aperfeiçoou os sistemas de bens de produção e de comunicação, a partir da invenção do computador."10

Neste sentido, a importância do conhecimento deve ser reconhecida, pois está presente em todos os ramos de atividade empresarial lucrativa, e também em ambientes que não possuem apenas um objetivo lucrativo.

As mudanças no desenvolvimento de estruturas tecnológicas ocorrem em tempo dinâmico, como no caso das frequentes alterações dos meios de comunicação, entre eles, telefonia móvel, internet, equipamentos de telecomunicação, televisões e computadores. Isso é fruto da atividade empresarial e seu investimento na produção de novas tecnologias que visam atender os interesses do mercado. A finalidade primordial de todo e qualquer estabelecimento empresarial é o ganho de capita $^{11}$, no entanto, nessa conjuntura, os investimentos em informação, desenvolvi-

${ }^{09}$ LISBOA, Roberto Senise. Proteção do consumidor na sociedade da informação. Revista do Direito Privado da UEL, v. 2, n. 1, p. 7, jan./abr. 2009. Disponível em: p 6-7. Disponível em: <www.uel.br/revistas/direitoprivado >. Acesso em: 01 maio 2018.

${ }^{10}$ Ibidem p.12.

${ }^{11}$ A empresa é o núcleo de múltiplas manifestações do direito de propriedade: produz bens, gera riqueza, estabelece - por meio dos negócios jurídicos - relações de aquisição e alienação de propriedade tecendo um intrincado conjunto de obrigações jurídicas e interagindo com o meio político, com os consumidores, com os trabalhadores, com as populações vizinhas, com a natureza. BESSA, Fabiane Lopes Bueno Netto. Responsabilidade Social das Empresas: práticas sociais e regulação jurídica. Rio de Janeiro: Lumen Júris, 2006, p. 101. 
mento tecnológico e proteção aos direitos ensejaram um novo modo de tratamento da atividade empresarial que se denominou nova empresarialidade. ${ }^{12}$

A Constituição Federal de 1988 trouxe em seu texto fundamentos para ordem econômica: a livre iniciativa, a livre concorrência e a proteção da ordem econômica, sendo que estas normas exercem papel fomentador e harmonizador para atividade empresarial. Contudo, é preciso compreender cada um destes fundamentos apresentados, que ao longo da história jurídica brasileira passaram por mudanças e implementações de novas posturas na proteção aos direitos, mais especificamente aqueles ligados à informação.

Quando se verifica então a atividade empresarial em ambiente informacional, se está a demonstrar que esta atividade pode estar sendo exercida em uma era posterior à pós-modernidade, sofrendo o impacto direto das tecnologias da informação e gerando a necessidade de se interpretar os fatos e as normas, com base em outras premissas que não apenas a antiga hipótese clara de que a empresa objetiva o lucro e assim deve ser vista numa visão unidimensional.

Parte-se, assim, para a ampliação da visão desta atividade empresarial para que possa comportar também o seu entorno. A visão teórica sobre stakebolders é adequada por levar em conta que não se deve desprezar na análise, independente de seu objetivo, as partes relacionadas que pululam ao largo da empresa.

\section{A LIVRE CONCORRÊNCIA, LIVRE INICIATIVA E A PROTEÇÃO DA ORDEM ECONÔMICA}

A ordem econômica, à luz da Constituição Federal de 1988, possui alguns fundamentos que norteiam a atividade empresarial, entre elas a livre iniciativa. ${ }^{13}$ Estes fundamentos traduzem a ideia de manutenção do círculo de produção, sendo

\footnotetext{
${ }^{12}$ A empresa atua para atender não somente os interesses dos sócios, mas também os da coletividade: Função, em direito, é um poder de agir sobre a esfera jurídica alheia, no interesse de outrem, jamais em proveito do próprio titular. Algumas vezes, interessados no exercício da função são pessoas indeterminadas e, portanto, não legitimadas a exercer pretensões pessoais e exclusivas contra o titular do poder. É nessas hipóteses, precisamente, que se deve falar em função social ou coletiva. [...] Em se tratando de bens de produção, o poderdever do proprietário de dar à coisa uma destinação compatível com o interesse da coletividade transmuda-se, quando tais bens são incorporados a uma exploração empresarial, em poder-dever do titular do controle de dirigir a empresa para a realização dos interesses coletivos. COMPARATO, Fábio Konder. Função social da propriedade dos bens de produção. São Paulo, Revista de Direito Mercantil, Industrial, Econômico e Financeiro, v. 63,1986, p. 44.

${ }^{13}$ Fundamentada no princípio da livre iniciativa, a Carta Magna brasileira reconhece a propriedade privada e a reserva da atividade econômica aos particulares, porém condiciona-as à dignidade da pessoa humana e à valorização do trabalho, e as dirige à construção de uma sociedade livre, justa e solidária. Isso deve ocorrer porque propriedade e livre iniciativa são apenas princípios-meios, e desta forma devem estar balizados no reconhecimento do valor da pessoa humana como fim. FARAH, Eduardo Teixeira. A disciplina da empresa e o princípio da solidariedade social. In: MARTINS-COSTA, Judith [Org.]. A Reconstrução do Direito Privado: reflexos dos princípios, diretrizes e direitos fundamentais constitucionais no direito privado. São Paulo: revista dos Tribunais, 2002, p. 676.
} 
que este é fundamental para uma maior quantidade de agentes econômicos que atuam na economia.

A livre iniciativa, por sua vez, representa a não interferência do Estado na possibilidade de entrada de agentes econômicos, em um determinado setor da economia, levando-se em consideração os limites jurídicos impostos pela legislação brasileira. ${ }^{14}$ José Afonso da Silva, nesse sentido, ensina que a livre iniciativa é

[...] num contexto de uma Constituição preocupada com a realização da justiça social (o fim condiciona os meios), não pode significar mais do que 'liberdade de desenvolvimento da empresa no quadro estabelecido pelo poder público, e, portanto, possibilidade de gozar das facilidades e necessidade de submeter-se às limitações postas pelo mesmo'. É legítima, enquanto exercida no interesse da justiça social. Será ilegítima, quando exercida com objetivo de puro lucro e realização pessoal do empresário. ${ }^{15}$

\section{Além disso, na concepção de Celso Ribeiro Bastos, a livre iniciativa}

[...] é uma manifestação dos direitos fundamentais e no rol daqueles devia estar incluída. De fato o homem não pode realizar-se plenamente enquanto não lhe for dado o direito de projetar-se através de uma realização transpessoal. Vale dizer, por meio da organização de outros homens com vistas à realização de um objetivo. Aqui a liberdade de iniciativa tem conotação econômica. Equivale ao direito de todos têm de lançarem-se ao mercado da produção de bens e serviços por sua conta e risco. Aliás, os autores reconhecem que a liberdade de iniciar a atividade econômica implica a de gestão e a de empresa. ${ }^{16}$

\section{Outro fundamento da ordem econômica é a livre concorrência que consiste} numa relação entre particular, cabendo ao Estado somente a proteção do equilíbrio nestas relações, mantendo, assim, os benefícios da atividade empresarial em prol da economia e da sociedade.

\footnotetext{
${ }^{14} \mathrm{O}$ princípio da livre iniciativa, por sua vez, pode ser decomposto em alguns elementos que lhe dão conteúdo, todos eles desdobrados no texto constitucional. Pressupõe ele, em primeiro lugar, a existência da propriedade privada, isto é, de apropriação particular dos bens e dos meios de produção (CF, art. $5^{\circ}$, XXII e 170, II). De parte isto, integra, igualmente, o núcleo da ideia da livre iniciativa a liberdade de empresa, conceito materializado no parágrafo único do art.170, que assegura a todos o livre exercício de qualquer atividade econômica, independentemente de autorização, salvo nos casos previstos em lei. Em terceiro lugar situa-se a livre concorrência, lastro para a faculdade e o empreendedor estabelecer os seus preços, que hão de ser determinados pelo mercado, em ambiente competitivo (CF, art. 170, IV). Por fim, é da essência do regime da livre iniciativa a liberdade de contratar, decorrência lógica do princípio da legalidade, fundamento das demais liberdades, pelo qual ninguém será obrigado a fazer ou deixar de fazer alguma coisa senão em virtude de lei (CF, art. $5^{\circ}$, II). BARROSO, Luiz Roberto. A ordem econômica constitucional e os limites à atuação estatal no controle de preços. Revista Eletrônica de Direito Administrativo Econômico (REDAE). Salvador, Instituto Brasileiro de Direito Público, n. 14, 2008, p.04.

${ }^{15}$ DA SILVA, José Afonso. Curso de Direito Constitucional Positivo. 15. ed. São Paulo: Malheiros, 1998, p. 760.

${ }^{16}$ BASTOS, Celso Ribeiro. Comentários à Constituição do Brasil., v. 7, São Paulo: Saraiva, 1990, p. 16.
} 
Um pressuposto da livre concorrência é a busca dos agentes econômicos pela posição suprema em face dos outros dentro de uma determinada atividade econômica, fazendo uso constante de técnicas que visam a melhora na qualidade da produção e prestação de serviços, ao mesmo tempo em que se reduzem custos e preços; do contrário, perderão cada vez mais espaço no mercado. Para Celso Ribeiro Bastos é preciso compreender a livre concorrência levando em consideração que

[...] por sua vez, também a esse respeito, afirma que "a livre concorrência é indispensável para o funcionamento do sistema capitalista. Ela consiste essencialmente na existência de diversos produtores ou prestadores de serviços. É pela livre concorrência que se melhoram as condições de competitividade das empresas, forçando-as a um constante aprimoramento dos seus métodos tecnológicos, dos seus custos, enfim, da procura constante de criação de condições mais favoráveis ao consumidor. Traduz-se, portanto, numa das vigas mestras do êxito da economia de mercado. O contrário da livre concorrência significa o monopólio e o oligopólio, ambos situações privilegiadora do produtor, incompatíveis com o regime de livre concorrência. ${ }^{17}$

A concorrência tem como premissa para sua manutenção, a existência de oportunidades de escolha quanto à variedade de produtos e serviços oferecidos aos consumidores. Desta maneira, a concorrência implementa a economia à medida em que suprime paulatinamente os produtos e serviços de qualidade inferior ou que possuam preço elevado da atividade econômica.

A livre concorrência, por sua vez, é um fator fundamental para o círculo produtivo tendo em vista a geração de favorecimento aos consumidores, elevação da produção nos mais variados setores e melhoria na qualidade dos produtos e serviços gerados. Por tais motivos, cabe ao Estado a intervenção evitando ofensas à concorrência por meio de formações de cartéis, oligopólios, monopólios, entre outras possíveis violações. ${ }^{18}$ No entanto, no caso de as transgressões ocorrerem, compete ao Estado aplicar os meios necessários e legais para restabelecer os ditames concorrenciais e sancionar os violadores do sistema da livre concorrência.

\footnotetext{
17 "Disciplina jurídica da concorrência - Abuso do poder econômico", Resenha Tributária, 1984, p. 119/120 Apud BASTOS, Celso Ribeiro; MARTINS, Ives Gandra. Comentários à Constituição do Brasil. v. 7, São Paulo, Saraiva, 1990, p. 25.

${ }^{18}$ [...] na democracia capitalista globalizada, de pouca serventia mostram-se os refinados instrumentos de proteção dos direitos humanos, postos à disposição pelo direito público, se as políticas públicas e a atividade econômica privada escaparem aos mecanismos de controle jurídico, incrementando a exclusão social e o desrespeito à dignidade da pessoa humana. Na era dos contratos de massa e na sociedade tecnológica, pouco eficazes mostram-se os mecanismos tradicionalmente empregados pelo direito civil. TEPEDINO, Gustavo. Direitos Humanos e Relações Jurídicas Privadas. In: TEPEDINO, Gustavo (Org.). Temas de Direito Civil. Rio de Janeiro: Renovar, 1999, p. 57.
} 
Luiz Otávio Pimentel trata deste sistema desenvolvimentista e dos fundamentos do sistema capitalista no Brasil em consonância com a garantia da propriedade privada intelectual e tecnológica.

Os princípios fundamentais do capitalismo são a livre concorrência e o livre comércio, a propriedade privada dos bens de produção e sua livre herança, seguidos de princípios que lhe são derivados, como os princípios de liberdade de mercado, de capitais e de pessoas. As funções do capitalismo são, portanto, a maximização dos benefícios e o seu próprio crescimento e desenvolvimento. Havendo um correto funcionamento do sistema, beneficiam-se e lucram os capitalistas. Para garantir o seu funcionamento nada melhor do que a garantia da propriedade privada, em especial a intelectual e tecnológica. ${ }^{19}$

A percepção a respeito destes fundamentos da ordem econômica indica a proteção em torno dos agentes econômicos, consumidores e dos direitos a eles inerentes, porém, na medida em que a relação entre atividade empresarial e novas tecnologias avança, essa proteção se torna fragilizada, surgindo, então, novos conceitos que, uma vez concretizados, possibilitariam a retomada do equilíbrio e a proteção de todos os atores integrantes deste cenário.

Os conceitos a serem criados são a função social da empresa e a nova empresarialidade - que significam a retomada de valores que outrora foram deixados de lado em prol da obtenção de ganho de capital. Esta percepção encontra respaldo no pensamento de Diogo de Figueiredo Moreira Neto que assim expõe:

O princípio da liberdade de iniciativa tempera-se pelo da iniciativa suplementar do Estado; o princípio da liberdade de empresa corrigese com o da definição da função social da empresa; o princípio da liberdade de lucro, bem como o da liberdade de competição, moderam-se com o da repressão e do abuso de poder econômico; o princípio da liberdade de contratação limita-se pela aplicação dos princípios de valorização do trabalho e da harmonia da solidariedade entre as categorias sociais de produção; e finalmente, o princípio da propriedade privada restringe-se como o princípio da função social da propriedade. ${ }^{20}$

O desenvolvimento destes institutos permitiu uma inovação na percepção dos interesses embutidos em toda atividade empresarial e novas finalidades para melhor desempenho destes em um cenário de sociedade da informação.

19 PIMENTEL, Luiz Otávio. Direito Industrial (As funções do Direito de Patentes). Porto Alegre: Síntese, 1999, p.110.

${ }^{20}$ MOREIRA NETO, Diogo de Figueiredo. Ordem econômica e desenvolvimento na Constituição de 1988. Rio de Janeiro: Apec, 1989. p.28. 


\section{FUNÇÃO SOCIAL DA EMPRESA E SUA RELAÇÃO COM A ATIVIDADE EMPRESARIAL}

As concepções em torno da função social da empresa são uma decorrência interpretativa das normas constitucionais que tratam da função social da propriedade e do contrato, em consonância com a lógica do sistema econômico brasileiro da produção capitalista.

Os constituintes de 1988, ao tratarem dos assuntos inerentes ao desenvolvimento econômico, entenderam ser necessária a manutenção dos meios de produção no controle dos particulares, assegurando, assim, a manutenção da propriedade privada.

O texto constitucional vigente estabeleceu a ruptura com a definição clássica da propriedade, de acordo com o que prevê a história do direito privado. Os ditames da propriedade no campo do direito privado estabelecia que se trata de um direito perpétuo e absoluto de seu titular e tinha como premissa nuclear uma relação entre o proprietário e a coisa, além do poder exclusivo sobre o bem.

As novas concepções acerca do Direito Público Ocidental, o impacto normativo da Constituição, ao longo do tempo, trouxe um novo paradigma para o tratamento da propriedade. ${ }^{21} \mathrm{O}$ direito de propriedade passa a ser compreendido como uma concessão realizada pela coletividade em prol de um determinado indivíduo. Assim temos um deslocamento do titular da propriedade como elemento principal, atribuindo este novo papel à sociedade. Luiz Roberto Barroso traduz essa concepção acerca da constitucionalização do direito.

A ideia de constitucionalização do Direito aqui explorada está associada a um efeito expansivo das normas constitucionais, cujo conteúdo material e axiológico se irradia, com força normativa, por todo o sistema jurídico. Os valores, os fins públicos e os comportamentos contemplados nos princípios e regras da Constituição passam a condicionar a validade e o sentido de todas as normas do direito infraconstitucional. Como intuitivo, a constitucionalização repercute sobre a atuação dos três Poderes, inclusive e notadamente nas suas relações com os particulares. Porém, mais original ainda: repercute, também, nas relações entre particulares. ${ }^{22}$

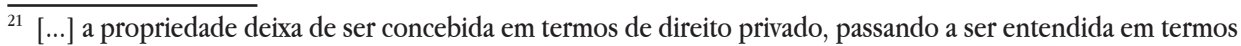
de função social. Se alguém duvidar disso, que medite sobre a recente legislação sobre aluguéis, que trata, com jeito, o aluguel e o arrendamento de casas como assunto afetado ao interesse público, em que tarifas de aluguel razoáveis devem ser fixadas, como se se tratasse de serviço de utilidade pública. Roscoe Pound apud CRETELLA JUNIOR, José. Elementos de Direito Constitucional. 4. ed. São Paulo: Revista dos Tribunais, 2001, p. 257

${ }^{22}$ BARROSO, Luiz Roberto. Fundamentos teóricos e filosóficos do novo direito constitucional brasileiro (Pósmodernidade, teoria crítica e pós-positivismo). Revista Diálogo Jurídico, Salvador, v. I. n. 6, 2004, p.39. 
Diante desta mudança de paradigma o Estado fará uma fiscalização acerca da destinação que o proprietário dará ao bem e, nas hipóteses constitucionais e legais em que não haja uma utilização vantajosa e prospectiva, para a coletividade. A intervenção é medida que se impõe, visando compelir o titular da coisa à utilização em conformidade com os preceitos fundamentais, sob pena de perda do domínio sobre a coisa. De acordo com o que sustenta Pietro Perlingieri, a constituição da função social se dá da seguinte forma:

A função social, construída como o conjunto dos limites, representaria uma noção somente de tipo negativo voltada a comprimir os poderes proprietários, os quais sem os limites, ficariam íntegros e livres. Este resultado está próximo à perspectiva tradicional. Em um sistema inspirado na solidariedade política, econômica e social e ao pleno desenvolvimento da pessoa o conteúdo da função social assume um papel de tipo promocional, no sentido de que a disciplina das formas de propriedade e as suas interpretações deveriam ser atuadas para garantir e para promover os valores sobre os quais se funda o ordenamento. ${ }^{23}$

A utilização vantajosa e prospectiva da propriedade privada denomina-se função social. É necessário esclarecer que a ausência da função social não é somente representada pela falta de produtividade de uma propriedade; o modo de produção e os meios empregados também podem configurar desrespeito à função social. A produção de substâncias psicotrópicas, a utilização de mão de obra sem a concessão dos direitos a ela inerentes, a ponto de se configurar a condição análoga de escravo, dentre outras são algumas hipóteses de afronta a função social da propriedade.

A função social da propriedade tem grande importância no texto Constitucional, mencionada em duas normas: no artigo 5. ${ }^{\circ}$, inciso XXII e no artigo 170, inciso III. Assim resta claro que a existência do direito de propriedade à luz da Constituição Federal de 1988 é em prol da sociedade.

O tratamento da função social na Constituição Brasileira não está restrita à propriedade, uma vez que por meio de uma interpretação seus reflexos alcançam o contrato e a atividade empresarial. O Código Civil Brasileiro dispõe, em seu artigo. 421, o seguinte: A liberdade de contratar será exercida em razão e nos limites da função social do contrato.

Cabe salientar, que a exposição dos motivos do anteprojeto do Código Civil Brasileiro 2002, de autoria de Miguel Reale, pode-se obter uma interpretação, do que consiste a função social do contrato.

\footnotetext{
${ }^{23}$ PERLINGIERI, Pietro. Perfis do Direito Civil. 3. ed. Rio de Janeiro: Renovar, 2007, p. 226.
} 
[...] tornar explícito, como princípio condicionador de todo o processo hermenêutico, que a liberdade de contratar só pode ser exercida em consonância com os fins sociais do contrato, implicando os valores primordiais da boa-fé e da probidade. Trata-se de um preceito fundamental, dispensável talvez sob o enfoque de uma estreita compreensão do Direito, mas essencial à adequação das normas particulares à concreção ética da experiência jurídica. ${ }^{24}$

A função social ${ }^{25}$ do contrato, de acordo com o Código Civil, não está apenas no disposto do artigo 421, uma vez que encontra amparo no parágrafo único do artigo 2.035 do mesmo texto legal, que prevê:

Art. 2.035. Parágrafo único. Nenhuma convenção prevalecerá se contrariar preceitos de ordem pública, tais como os estabelecimentos por este Código para assegurar a função social da propriedade e dos contratos.

Os sistemas econômico e político nacional estão sustentados nos fundamentos da ordem econômica, ou seja, na livre iniciativa e na propriedade privada que, por sua vez, encontram substrato no contrato. Ao se atribuir uma função social à propriedade de acordo com o artigo 170 da Constituição Federal ${ }^{26}$, é preciso compreender os impactos da principiologia da função social dos contratos, tendo em vista que o contrato é uma das bases da propriedade. Isto significa que a função social do contrato foi configurada a partir da função social da propriedade.

A Constituição, segundo Konrad Hesse possui "força normativa" que consiste na irradiação das normas jurídicas constitucionais por todo o ordenamento jurídico vigente. Neste sentido, é possível perceber que a sistemática do regramento e da principiologia constitucional brasileira, seguem os mesmos moldes da teoria da força normativa da Constituição.

A Constituição Federal de 1988 ao tratar da livre concorrência, livre iniciativa e função social da propriedade, permitiu que a atividade empresarial ganhasse

\footnotetext{
${ }^{24}$ REALE, Miguel. O projeto do novo Código Civil brasileiro. 2. ed.São Paulo: Saraiva, 1999.p.71 Apud TARTUCE, Flavio. Função Social dos Contratos: do Código de Defesa do Consumidor ao novo Código Civil. São Paulo: Método, 2005, p.196.

${ }^{25}$ Eduardo Tomasevicius Filho trata da mesma maneira os aspectos da função social da empresa ao dizer que: a função social da empresa constitui o poder-dever de o empresário e os administradores da empresa harmonizarem as atividades da empresa, segundo o interesse da sociedade, mediante a obediência de determinados deveres, positivos e negativos. TOMASCEVICIUS FILHO, Eduardo. A Função social da empresa. Revista dos Tribunais, São Paulo, n. 92, p. 33-50, abr. 2003, p. 40.

${ }^{26}$ Art. 170. A ordem econômica, fundada na valorização do trabalho humano e na livre iniciativa, tem por fim assegurar a todos existência digna, conforme os ditames da justiça social, observados os seguintes princípios: I - soberania nacional; II - propriedade privada; III - função social da propriedade;
} 
um novo patamar de proteção. Portanto, as normas fundamentais do direito brasileiro orientam o ordenamento jurídico infraconstitucional.

Deste cenário surge a função social da empresa que, nas palavras de Rodrigo Almeida Magalhães, "não pode predominar sobre os direitos e interesses individuais, cabendo apenas conciliar os interesses da empresa com os da sociedade."27 Ademais, Maria Christina de Almeida, citando Waldírio Bulgarelli, preceitua que a "função social da empresa deve ser entendida como o respeito aos direitos e interesses dos que se situam em torno da empresa" ${ }^{28}$ Os valores constitucionais refletiram na atividade empresarial, exigindo desta uma atuação não apenas voltada aos interesses financeiros decorrentes do seus exercícios e da sua produção mas, também, aos interesses coletivos. Este conjunto de entendimentos encontra amparo nas lições de Fábio Konder Comparato que, ao tratar do tema função social, explica que

[...] função, em direito, é um poder de agir sobre a esfera jurídica alheia, no interesse de outrem, jamais em proveito do próprio titular. [...] É nessas hipóteses que se deve falar em função social ou coletiva. [...] em se tratando de bens de produção, o poder-dever do proprietário de dar à coisa uma destinação compatível com o interesse da coletividade transmuda-se, quando atais bens são incorporados a uma exploração empresarial, em poder-dever do titular do controle de dirigir a empresa para a realização dos interesses coletivos. ${ }^{29}$

Diante deste primeiro novo instituto, desenvolvido a partir da interpretação conforme a Constituição Federal, abriu-se espaço para a tratativa de uma nova empresarialidade, congregando os valores fundamentais aos fins primordiais da atividade empresarial.

\section{A NOVA EMPRESARIALIDADE NA SOCIEDADE DA INFORMAÇÃO: ENTRE A IDEOLOGIA E A UTOPIA}

A atuação parlamentar ao redor do Mundo Ocidental vem coibindo práticas abusivas na internet, incluindo condutas delitivas. A nova empresarialidade tem por

${ }^{27}$ MAGALHÃES, Rodrigo Almeida. A função social da empresa. Revista Magister de Direito Empresarial, Porto Alegre, v. 5, n. 28, p. 5-12, 2009, p. 11.

${ }^{28}$ ALMEIDA, Maria Christina de. A função social da empresa na sociedade contemporânea: perspectivas e prospectivas. Revista de Direito Argumentum, v. 3, 2003, p. 141.

${ }_{29}$ COMPARATO, Fabio Konder. Estado, Empresa e Função Social. São Paulo: RT, 1996, p. 38-46 
objetivo o exercício da atividade mercantil a partir de uma ética empresarial..$^{30} \mathrm{O}$ mundo globalizado tem em seu contexto desafios de maior dificuldade, constantes transformações e uma série de incertezas que tencionam as relações empresariais e que fomentarão soluções de negócios, inovação e vantagens competitivas, conforme explana Margarida Kunsch:

Em face dos grandes desafios, das transformações e das incertezas que estamos vivendo neste mundo globalizado, dominado pela revolução e convergência tecnológica da informação, as organizações estão sempre buscando se adaptar e reformatando constantemente suas estruturas funcionais e estratégias de ação. A criação de uma nova arquitetura organizacional visa exatamente criar mecanismos que integrem forças humanas, materiais e financeiras na busca de soluções negociais e vantagens competitivas para vencer um mundo complexo e de mercados difíceis. ${ }^{31}$

No campo dos conflitos, as empresas têm adotado cada vez mais mecanismos alternativos ao Poder Judiciário, dentre eles, negociações, automediações, mediações, arbitragem. Dentro deste contexto, não basta que se tenha como certa e absoluta, a exemplo, a aplicabilidade do Código de Defesa dos Consumidores, nas relações de consumo tomadas em autoestrada informacional como previsto no marco civil da internet (lei 12.965/2014) pois, observa-se a insuficiência destas regras protetivas de consumidores nas operações de internet, quando em relações transfronteiriças.

Neste sentido, Adriano Roberto Vancim e Fernando Frachone Neves reforçam as disposições principiológicas do Marco Civil da Internet a respeito da proteção da privacidade e da intimidade dos seus usuários. O uso constante da rede gera uma superexposição e a existência de legislação específica neste sentido proporcionou um pouco mais de segurança, tendo em vista que a vulnerabilidade diante do tráfego digital pode comprometer em alguma medida a vida das pessoas. ${ }^{32}$

Os autores asseveram dentro deste plano principiológico que "deve ser resguardado todas as informações possíveis de maneira a garantir a intimidade e privacidade das relações havidas na rede, notadamente porque tais informações, se

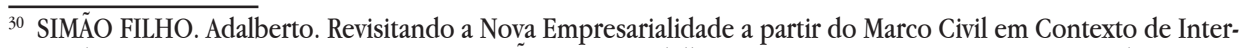
net das Coisas. In: DE LUCCA, Newton; SIMÃO FILHO, Adalberto; LIMA, Cintia Rosa Pereira. (Coord.). Direito \& Internet III: Tomo II. Marco Civil da internet (Lei n. 12.965/2014. São Paulo: Quartier Latin. 2015, p.27.

${ }^{31} \mathrm{KUNSCH}$, Margarida Maria Krohing. Planejamento de Relações Públicas na Comunicação Integrada: 4.ed. São Paulo: Summus, 2003, p.64.

32 VANCIM, Adriano Roberto. NEVES, Fernando Frachone. Marco Civil da Internet. 2. ed. Leme, SP: Mundo Jurídico. 2015, p.69. 
acessadas indiscriminadamente por terceiros, poderia servir de base para práticas infringentes, vedadas em lei." ${ }^{33}$

Assim sendo, cabe apresentar a nova empresarialidade como uma forma de contribuição para o desenvolvimento de um padrão de cunho ético para com relação ao comércio eletrônico transfronteiriço, independente do esforço legislativo de países alinhados.

Diante da realidade tecnológica em que vivemos, a circulação de informações aumentou, o mercado se encontra cada vez mais acirrado e competitivo e os investimentos em inovação cresceram, convergindo para situações que demandam maior proteção e segurança.

Com o progresso industrial e o acirramento da concorrência, os economistas perceberam o valor do "saber fazer" e surgiram novas necessidades dos comerciantes, os quais passaram a desejar uma alternativa de privilégio, que lhes desse maior liberdade e mesmo "privacidade", uma vez que a patente, dado seu caráter totalmente público, apresenta, a par das vantagens apresentadas pela proteção reconhecida mediante título, a exigência de exposição do segredo e a limitação temporal e espacial. Percebe-se aí, também, mais que a segurança do país, está em foco a competitividade individual da empresa. ${ }^{34}$

A calibração da conduta de forma tal a suprir as necessidade do consumidor brasileiro seria um ideal a ser perseguido a todas as empresas que queiram ter relações comerciais digitais com o Brasil. Por esta razão que encampamos a ideia já em desenvolvimento em alguns países europeus e na América do Norte de uma autorregulação de condutas que se constroem em ambientes digitais.

Sidney Guerra aborda a fragilidade que o direito à privacidade sofre no ambiente digital da internet. Segundo o autor, "a medida que a pessoa se dispõe a "navegar" pela internet, sua privacidade fica extremamente comprometida. É que com cada clique do mouse a pessoa vai deixando seu caminho marcado pela rede e, consequentemente, os seus hábitos, seus vícios, suas necessidades e suas preferências". ${ }^{35} \mathrm{O}$ mencionado autor explica a questão que envolve o armazenamento de dados e informações dos usuários da internet e a potencialidade dos riscos ali contidos.

\footnotetext{
33 VANCIM, Adriano Roberto. NEVES, Fernando Frachone. Marco Civil da Internet. 2. ed. Leme, SP: Mundo Jurídico. 2015, p.69.

${ }^{34}$ FEKETE, Elisabeth Kasznar. O Regime Jurídico do Segredo de Indústria e Comércio no Direito Brasileiro. Rio de Janeiro: Forense, 2003, p. 30.

35 GUERRA, Sidney. O Direito à Privacidade na Internet. América Jurídica, 2004, p.78.
} 
O armazenamento de informações sobre uma determinada pessoa é, assim, algo inquietante em razão da ameaça de que estes dados possam ser acessados indevidamente, dado que os cookies são responsáveis pelo armazenamento das informações pessoais dos usuários da internet, pois abrem caminho até o disco rígido do internauta e armazenam ali um arquivo de texto que identifica o computador com um número único. ${ }^{36}$

O armazenamento dos dados é um risco iminente para os usuários, comprometendo a intimidade e a privacidade das pessoas. O marco civil e sua natureza protetiva estabelecem a exigência de autorização expressa para que tais conteúdos sejam utilizados, sob pena de responsabilização de quem indevidamente dispor dos dados.

Esta nova empresarialidade que absorverá este sistema nas relações de comércio eletrônico transfronteiriças observará a agregação de valores de natureza moral e ética nas relações empresariais, propiciando um afastamento de lacunas protetivas e reduzindo a aplicações de sanções ou métodos coercitivos. ${ }^{37}$

A principiologia empresarial com base em raízes éticas e valoração dos direitos humanos traduzida na nova empresarialidade, enfrenta ainda, um outro paradoxo que consiste na proteção dos direitos do usuário, no que se relaciona à privacidade quando acabou por se tornar prática a utilização dos dados maciços produzidos no espaço digital, por processadores no modelo big data, sem se atentar para com relação à autorização do consumidor ou, ainda, a sensibilidade destes dados.

Deste dilema, surge a preocupação acerca do que é feito com essa base de dados maciços e, além disso, como ficam a segurança social e a privacidade dos indivíduos, garantidos constitucionalmente. Diante deste cenário surgem indagações: 1) Por que nos vigiam? 2) Quem nos vigia? 3) O que fazem com nossos dados? 4) Como nos vigiam? ${ }^{38}$ A realidade se apresenta como um panóptico, isto é, um sistema que enxerga tudo e a todos os momentos e isso provoca uma supressão dos sub-representados, a partir do controle dos dados destes grupos. ${ }^{39}$

Esse controle alcança todos aqueles que não seguem as ordens do sistema ou tenta burlá-los e desta maneira comprometem a privacidade e os direitos humanos sob o fundamento de se gerar segurança sistêmica esse "proteger o grupo".

\footnotetext{
$\overline{36}$ GUERRA, Sidney. O Direito à Privacidade na Internet. América Jurídica, 2004, p.81.

${ }^{37}$ SIMÃO FILHO, Adalberto. Revisitando a Nova Empresarialidade a partir do Marco Civil em Contexto de Internet das Coisas. In: DE LUCCA, Newton; SIMÃO FILHO, Adalberto; LIMA, Cintia Rosa Pereira. (Coord.). Direito \& Internet III: Tomo II. Marco Civil da internet (Lei n. 12.965/2014. São Paulo: Quartier Latin. 2015, p.30.

${ }^{38}$ Idem, p.34.

${ }^{39}$ Idem.
} 
Por meio destes mecanismos de controle e vigilância, gera-se a facilidade na padronização dos perfis dos cidadãos em razão dos dados estruturados e não estruturados que são captados em tempo real. A nova empresarialidade traz em seu teor uma carga valorativa a ser implementada, quais sejam, o solidarismo, a eticidade e a cooperação a demonstrar que por estas razões, um empresário que estivesse imbuído destes princípios, deveria ter cuidados com dados sensíveis que lhes foram depositados por usuários, independente da forma.

Mesmo que a "garimpagem" de dados digitais seja uma prática em crescimento, não se pode afastar dos ideais protetivos e de um tratamento regulado e adequado destes dados. Se o sistema é insuficiente para esta regulação, que se faça por força de compromisso ético.

Maria Tardelli Azevedo salienta a respeito do tratamento que se deve dar à ética e à responsabilidade dentro da atividade empresarial.

Ética é a base da Responsabilidade Social e se expressa através dos princípios e valores adotados pela organização. Não há Responsabilidade Social sem ética nos negócios. Não adianta uma empresa, por um lado pagar mal seus funcionários, corromper a área de compras de seus clientes, pagar propinas a fiscais do governo e, por outro, desenvolver programas junto a entidades sociais da comunidade. Essa postura não condiz com uma empresa que quer trilhar um caminho de Responsabilidade Social. É importante seguir uma linha de coerência entre ação e discurso. ${ }^{40}$

Há um progresso da sociedade consumista e a atividade empresarial vem contribuindo para redução das desigualdades, pobreza e da exclusão digital e social. Manuel Castells enfatiza que a competitividade econômica gera sofrimento e desigualdades sociais. ${ }^{41}$ No mesmo sentido, Rubens Requião ensina que

Hoje o conceito social de empresa, como o exercício de uma atividade organizada, destinada à produção ou circulação de bens ou de serviços, na qual se refletem expressivos interesses coletivos, faz com que o empresário comercial não seja mais o empreendedor egoísta, divorciado daqueles interesses gerais, mas um produtor impulsionado pela persecução de lucro, é verdade, mas consciente de que constitui uma peça importante no mecanismo da sociedade humana. Não é ele, enfim, um homem isolado, divorciado dos anseios gerais da sociedade em que vive. ${ }^{42}$

\footnotetext{
${ }^{40}$ AZEVEDO, Maíra Tardelli de. Publicidade cidadã: como comunicar responsabilidade social empresarial. In: Responsabilidade social das empresas: contribuição das universidades. São Paulo: Peirópolis; Instituto Ethos, 2004, p.6.

${ }^{41}$ CASTELLS, Manuel. Fim de milênio. São Paulo: Paz e Terra, 2012, p, 95.

${ }^{42}$ REQUIÃO, Rubens. Curso de Direito Comercial. 25. ed. São Paulo: Saraiva, 2003, p.76.
} 
Assim, o exercício da nova empresarialidade não objetiva, em hipótese alguma, afastar o lucro legítimo como busca finalista da atividade empresarial, mas contribui para que se possa, no exercício da atividade mercantil, assumir compromissos com a responsabilidade social. ${ }^{43}$ Esta possibilidade contribui para o desenvolvimento social e econômico sustentável, como mencionamos:

[...] as buscas [das empresas] não sejam tão só do lucro, mas também de resultados que podem ser econômicos ou financeiros ou de qualquer outra natureza, inclusive social. A busca destes resultados, não interfere na procura da lucratividade, pelo contrário, dependendo da forma como a questão for internalizada no seio da empresa, poderá resultar no sensível acréscimo do lucro. ${ }^{44}$

A nova empresarialidade é uma decorrência da atividade empresarial e seu exercício ocorre no âmbito dos padrões éticos e valores objetivos que norteiam o relacionamento interno dos agentes do mercado. Além disso, é preciso ter em mente o que assevera Gladston Mamede, que trata a proteção da empresa não simplesmente na preservação dos interesses do empresário, porém a tutela de inúmeros interesses, entre eles o da comunidade e do estado também. O autor salienta os fatores de produção e as riquezas produzidas em razão da atividade empresarial desenvolvida como pontos a serem protegidos.

A proteção da empresa, portanto, não é mera proteção do empresário, nem da sociedade empresária, mas também proteção da comunidade e do Estado que se beneficiam - no mínimo indiretamente - com a produção de riquezas. Aliás, não apenas o empreendedor, o empresário, mas também os terceiros que mantenham relações negociais com a empresa e cujos direitos e interesses possam ser também afetados pela função social da empresa, a exemplo do que se tem nas hipóteses de recuperação judicial ou extrajudicial, bem como de falência [...]. Fica claro, nessa toada, que o princípio da função social da empresa reflete-se tanto a favor, quanto em detrimento do empresário ou dos sócios da sociedade empresária, já que se retira deles a faculdade de conservação ou exercício arbitrário da empresa, temperando a titularidade desta com interesses públicos, o que [...] recomenda ao jurista prudência, bom-senso, para equilibrar

\footnotetext{
${ }_{43}[\ldots]$ por outro lado, acrescenta o Instituto Ethos (2001) que a lógica do lucro inclui, hoje, a lógica da responsabilidade social. Como se observa, a empresa, nos dias atuais, está sendo levada a incorporar em suas atribuições, além da geração do lucro - considerada fundamental por Friedman (1977) -, a preocupação com o social. Essa "nova" empresa tem sido chamada de "empresa socialmente responsável". ARNOLDI, Paulo Roberto Colombo. Novos enfoques da função social da empresa numa economia globalizada. Revista do Mercosul, Buenos Aires, n.1. p.247-252, fev. 2000, p. 216-226.

${ }_{44}$ SIMÃO FILHO, Adalberto. A nova empresarialidade. Revista do Instituto dos Advogados de São Paulo, São Paulo, v. 9, n.18, p.05-46, jul./dez. 2006, p.46.
} 
os valores opostos, exigindo-lhe equidade (aequitas) 298 (original não grifado). ${ }^{45}$

A nova empresarialidade pode ser vista como uma ideologia a ser implementada no cenário empresarial e precisa ser melhor compreendida e concretizada com vistas a poder gerar benefícios sociais reais e não utópicos.

A ideologia embutida neste conceito trata do alcance das relações éticas em consonância com a lucratividade do estabelecimento comercial. ${ }^{46} \mathrm{O}$ respeito, a conscientização dos direitos e deveres, entre outros padrões éticos de conduta, vez que implementada nas práticas empresariais possibilitam a otimização nos resultados financeiros e na produtividade dos funcionários.

\section{CONSIDERAÇÕES FINAIS}

É possível sustentar que a ética e atividade empresarial geram uma completa sinergia, tornando viva a empresa e, por sua vez, atribuindo-lhe valor real. A atividade empresarial utiliza-se das ferramentas disponíveis pela internet e da rede mundial de computadores e, consequentemente, recebe a proteção quanto aos princípios constitucionais que norteiam a atividade econômica.

Existe uma relação da liberdade dos modelos de negócios na internet com a ordem econômica aqui já explicada, no entanto, no exercício da atividade empresarial, devem ser observados os condicionantes e princípios estabelecidos no marco civil da internet ou outros institutos previstos no ordenamento jurídico e tratados internacionais que possam levar à proteção dos consumidores e dos mercados, limitando o pleno exercício destes direitos.

A rede de computadores não pode ser vista de forma deletéria ao mercado, ademais a sua natureza participativa propicia o estabelecimento de padrões de conduta que respeitem os direitos de todo aquele que participe.

Em tempos rudes como estes que atravessamos, aparentando o descumprimento generalizado da lei além de práticas abusivas e lesivas aos consumidores,

$\overline{45}$ MAMEDE, Gladston. Direito empresarial brasileiro: empresa e atuação empresarial. 4. ed. v. 1. São Paulo: Atlas, 2010, p. 54.

${ }^{46}$ A ideologia se confunde com o conjunto das idéias, conceitos e representações que não se classificam sob a etiqueta de ciência. Elas não são nem verdadeiras nem falsas e não respondem, ao menos em primeiro lugar, a uma necessidade de conhecimento. Mas elas são indispensáveis. Acompanham a visa social como uma espécie de respiração. BOUDON, Pierre. A Ideologia: ou a origem das ideias recebidas. São Paulo: Ática, 1989, p. 27. 
acompanhadas de atos de corrupção de todas as matizes, pode-se imaginar que a ideia da construção de uma nova empresarialidade pautada em valores éticos e sociais e em princípios como o solidarismo e o cooperativismo internacional seja uma utopia tal que jamais seria implantada.

O alcance deste ideal passa pela pulverização dos constantes erros e ajuste das forças sociais com vistas à reconstrução do país de forma tal que se possa gerar um ambiente de crescimento sustentável, propício para o florescimento de uma nova empresarialidade benéfica e inclusiva.

\section{REFERÊNCIAS}

ALMEIDA, Maria Christina de. A função social da empresa na sociedade contemporânea: perspectivas e prospectivas. Revista de Direito Argumentum, v. 3, 2003.

ARNOLDI, Paulo Roberto Colombo. Novos enfoques da função social da empresa numa economia globalizada. Revista do Mercosul, Buenos Aires, n.1. p. 247-252, fev. 2000.

AZEVEDO, Maíra Tardelli de. Publicidade cidadã: como comunicar responsabilidade social empresarial. In: Responsabilidade social das empresas: contribuição das universidades. São Paulo: Peirópolis; Instituto Ethos, 2004.

BARROSO, Luiz Roberto. Fundamentos teóricos e filosóficos do novo direito constitucional brasileiro (Pós-modernidade, teoria crítica e pós-positivismo). Revista Diálogo Jurídico, Salvador, CAJ - Centro de Atualização Jurídica, v. I. n. 6, 2004.

BARROSO, Luiz Roberto. A ordem econômica constitucional e os limites à atuação estatal no controle de preços. Revista Eletrônica de Direito Administrativo Econômico (REDAE). Salvador, Instituto Brasileiro de Direito Público, n. 14, 2008.

BASTOS, Celso Ribeiro; MARTINS, Ives Gandra. Comentários à Constituição do Brasil, v. 7, 1990.

BESSA, Fabiane Lopes Bueno Netto. Responsabilidade Social das Empresas: práticas sociais e regulação jurídica. Rio de Janeiro: Lumen Júris, 2006. 
BOUDON, Pierre. A Ideologia: ou a origem das ideias recebidas. São Paulo: Ática, 1989.

BRASIL. Lei $\mathrm{n}^{\mathrm{0}} 12.965$, de 23 de abril de 2014. Estabelece princípios, garantias, direitos e deveres para o uso da internet no Brasil. Diário Oficial [da] República Federativa do Brasil, Poder Legislativo, Brasília, DF, 23 abr. 2014. Disponível em: < http://www.planalto.gov.br/CCIVIL_03/_Ato2011-2014/2014/Lei/L12965.htm>. Acesso em: 01.maio .2018

CASTELLS, Manuel. Fim de milênio. São Paulo: Paz e Terra,2012.

COMPARATO, Fábio Konder. Função social da propriedade dos bens de produção. São Paulo, Revista de Direito Mercantil, Industrial, Econômico e Financeiro, v. 63, 1986.

COMPARATO, Fabio Konder. Estado, Empresa e Função Social. São Paulo: RT, 1996.

CRETELLA JUNIOR, José. Elementos de Direito Constitucional. 4. ed. São Paulo: Revista dos Tribunais, 2001.

DA SILVA, José Afonso. Curso de Direito Constitucional Positivo. 15. ed. São Paulo: Malheiros, 1998.

DE LUCCA, Newton; SIMÃO FILHO, Adalberto; LIMA, Cintia Rosa Pereira. (Coord.). Direito \& Internet III: Tomo II. Marco Civil da internet (Lei n. 12.965/2014. São Paulo: Quartier Latin. 2015.

FEKETE, Elisabeth Kasznar. O Regime Jurídico do Segredo de Indústria e Comércio no Direito Brasileiro. Rio de Janeiro: Forense, 2003.

GUERRA, Sidney. O Direito à Privacidade na Internet. America Jurídica, 2004.

HAUBEN, Michael. Behind the net: the untold history of the ARPANET and computer science. 1995. Disponível em: < http://www.columbia.edu/ rh120/ch106. x07>. Acesso em: 01.05.2018. 
KUNSCH, Margarida Maria Krohing. Planejamento de Relações Públicas na Comunicação Integrada: 4. ed. São Paulo: Summus, 2003.

LISBOA, Roberto Senise. PROTEÇÃO DO CONSUMIDOR NA SOCIEDADE DA INFORMAÇÃO. Revista do Direito Privado da UEL, v. 2, n. 1, p. 7, jan./abr. 2009. Disponível em: <www.uel.br/revistas/direitoprivado>. Acesso em 01.05.2018.

MAGALHÃES, Rodrigo Almeida. A função social da empresa. Revista Magister de Direito Empresarial, Porto Alegre, v. 5, n. 28, p. 5-12, 2009.

MAMEDE, Gladston. Direito empresarial brasileiro: empresa e atuação empresarial. 4. ed. São Paulo: Atlas, 2010. v. 1.

MARTINS-COSTA, Judith (Org.). A Reconstrução do Direito Privado: reflexos dos princípios, diretrizes e direitos fundamentais constitucionais no direito privado. São Paulo: Revista dos Tribunais, 2002.

MOREIRA NETO, Diogo de Figueiredo. Ordem econômica e desenvolvimento na Constituição de 1988. Rio de Janeiro: Apec, 1989.

PAESANI, Liliana Minardi (Coord.). Direito e Internet: liberdade de informação, privacidade e responsabilidade civil. 6. ed. São Paulo: Atlas, 2013.

PERLINGIERI, Pietro. Perfis do Direito Civil. 3. ed. Rio de Janeiro: Renovar, 2007.

PIMENTEL, Luiz Otávio. Direito Industrial (As funções do Direito de Patentes). Porto Alegre: Síntese, 1999.

REQUIÃO, Rubens. Curso de Direito Comercial. 25. ed. São Paulo: Saraiva, 2003.

SIMÃO FILHO, Adalberto. A nova empresarialidade. Revista do Instituto dos Advogados de São Paulo, São Paulo, v. 9, n.18, p. 5-46, jul./dez. 2006.

TAKAHASHI, Takeo (Org.). Sociedade da informação no Brasil: livro verde. Brasília: Ministério da Ciência e Tecnologia, 2000.

TARREGA, Maria Cristina Vidotte Blanco; VIDOTTE, Adriana; TAVARES NETO, José Quirino (Org.). Estado, empresa e desenvolvimento econômico. Florianópolis: Fundação Boiteux, 2008. 
TARTUCE, Flavio. Função Social dos Contratos: do Código de Defesa do Consumidor ao novo Código Civil. São Paulo: Método, 2005.

TEPEDINO, Gustavo. Direitos Humanos e Relações Jurídicas Privadas. In: TEPEDINO, Gustavo (Org.). Temas de Direito Civil. Rio de Janeiro: Renovar, 1999.

TOMASCEVICIUS FILHO, Eduardo. A Função social da empresa. Revista dos Tribunais, São Paulo, n. 92, p. 33-50, abr. 2003.

VANCIM, Adriano Roberto. NEVES, Fernando Frachone. Marco Civil da Internet. 2. ed. Leme, SP: Mundo Jurídico, 2015.

Recebido em: 03 de março de 2018 Aceito em: 24 de julbo de 2018 